\title{
ABUNDANCE OF EGGPLANT (Solanum melongena L.) FLOWER VISITORS IN LALITPUR, NEPAL
}

\author{
R. P. Mainali ${ }^{1}$, R. B. Thapa ${ }^{2}$ and Y. P. Giri ${ }^{1}$ \\ ${ }^{1}$ Nepal Agricultural Research Council, Kathmandu, Nepal, ${ }^{2}$ Institute of Agriculture and Animal \\ Sciences, Tribhuvan University, Nepal
}

\begin{abstract}
In order to determine the abundance of insect flower visitors in growing crop of eggplant, Solanum melongena L., a field experiment was conducted in Khumaltar, Laliptur during summer-rainy season of 2012 to 2014 . The insect flower visitors were monitored weekly by end-to-end walk method using sweep net at different time of the day, viz. 7-8 am, 12-1 pm and 4-5 pm. Then collected insects were identified using the reference insects/books available in Insect Museum of Entomology Division, NARC, Khumaltar. This study revealed that Hymenopteran were found to be the most dominant (90.75\%) flower visitors; followed by Lepidopteran insects $(9.25 \%)$. Among the identified insect species, Bombus sp. (60.22\%) was the most frequently collected bees as flower visitor of eggplant followed by Apis mellifera L., A. cerana F., Syntomis sp. in all three years of field study. Other flower visitors, such as Anthophora sp., Andrena sp. and Halictus sp. were also found visiting the eggplant flower but their occurrence was minimal. Significantly $(\mathrm{p}<0.05)$ higher number of insects visited the eggplant flowers at 7-8 am $(58.48 \%)$ followed by those visiting during 4-5 pm (28.97\%) and 12-1 pm (12.54\%), respectively. For adequate pollination and healthy production of eggplant, conservation and utilization of flower visitors and their role in pollination is imperative.
\end{abstract}

Key words: monitoring, Bombus sp., eggplant, flower visitors

\section{INTRODUCTION}

Pollination is an essential service for the reproduction of most species of flowering plants and ultimately to the foods (Nunes-Silva et al., 2010). Fruit, vegetable or seed production from 87 of the leading global food crops is dependent upon animal pollination (Klein et al., 2007). An over 80 percent pollination activity is performed by insects and moreover insects including bee group are vital for the pollination of many cultivated and wild plants (Thapa, 2006).

The increasing demand for food and the "Pollination crisis" have emphasized the importance of better understanding the potential of pollinators for pollinating crops (Patricio et al., 2012). In eggplant, quality and quantity of fruit and seed was enhanced by insect visitation (Miyamoto et al., 2006; Gemmill-Herren and Ochieng, 2008; Patricio et al., 2012) and pollen complementation (Patricio et al., 2012). Even in cover cultivation, the highest yield in eggplant was achieved when applying insects as natural pollinators (Kowalska, 2008).

The farmers of Nepal now-a-days are doing offseason vegetable production in protective structure where pollinators have no access to visit flowers frequently. Even in natural condition, the diversity and abundance of pollinators are highly affected by indiscriminate use of pesticides by human. In such conditions to get sustainable yield, pollinators either should be conserved or effective one should be reared and introduced in to the field. But, only sparsely literatures are available in these aspects in the context of Nepal. Long-term systematic monitoring is required for the creation of data on local pollinators for future endeavor. Therefore, this monitoring was carried out for the determination of the diversity and abundance of eggplant flower visitors as well as appropriate foraging time as a baseline study for future advance study. 


\section{MATERIALS AND METHODS}

The study was carried out in the research field of Entomology Division, NARC, Khumaltar by growing eggplant in 0.2 acres of land. The research field lies in valley of mid hills under central development region of Nepal, having sub-tropical climate, with an average annual rainfall of 1122 $\mathrm{mm}$ distributed all over the year. The average temperature and relative humidity range from -1.37 to $32.79^{\circ} \mathrm{C}$ and 35.37 to 100 percent over the year, respectively.

The monitoring on abundance of flower visitors was done after the flowering of 50 percent eggplants during summer-rainy season (second fortnight of April to second fortnight of August) of 2012, 2013 and 2014 AD. The insect flower visitors were collected weekly at different hours of the day, viz. 7-8 am, 12-1 pm and 4-5 pm by end-to-end walk method using sweep net with very low constant speed. For each day hour, 4 end to end walks, each of 20 meter was allocated. It was adjusted in such a way that each walk received 20 sweeps. These collected insects were killed in jars charged with ethyl acetate and taken to Insect Museum of Entomology Division, Khumaltar. The eggplant flower visitors were identified with the help of reference insects and books related to taxonomy those were available in the museum.

The data obtained were entered into the Microsoft Office Excel, analyzed and interpreted. The Analysis of Variance (ANOVA) was conducted to calculate the difference in the flower visitation over time as treatment using GEN-STAT, Discovery Edition. For significant differences among the treatments, Duncan Multiple Range Test (DMRT) was used to differentiate treatments effect at $\mathrm{p}<0.05$ as described by Duncan (1951).

\section{RESULTS AND DISCUSSION}

In total, 397, 452 and 284 flower visitors were recorded in 2012, 2013 and 2014, respectively. Over the period of three years field studies, a total of two Orders, four Families and seven species were recorded as flower visitors of eggplants (Table 1). Ninety percent insects visiting eggplant flowers were from Order Hymenoptera and most of them from Family Apidae. Bodlah and Waqar (2013) reported that Hymenopteran insects were more diverse and found to be foraging eggplant flowers efficiently. They also reported that the family Apidae was the most dominant flower visitors of eggplant, bitter gourd and ridge gourd.

The bumble bee, Bombus sp. was the most dominant visitor $(60.22 \%)$ of eggplant flower in all three year of field study, which was followed by domestic bees and others (Table 1, Figure 1). Similar results are reported by Montemor and Souza (2009) and Patricio et al. (2012), where they identified Bombus sp. as potential and important pollinators of eggplants. Bombus is known to provide effective fruit setting in eggplant cultivation (Abak et al., 1995).

After bumble bees, the domesticated bees were found to be visiting flower of eggplant more frequently. Patricio et al. (2012) also reported Apis mellifera L. as pollinators of eggplant. Bodlah and Waqar (2013) observed three species of pollinators visiting eggplant including Bombus sp. Halictus sp. and an un-identified species from Halictidae family.

All types of flower visitors visited eggplant flower significantly higher in number during morning time than in the evening and day time (Table 2). Over half of recorded insects $(58.48 \%)$ visited eggplant flower at morning hour 7-8 am, around one-fourth (28.97\%) visited at evening hour 4-5 pm and very low number of insects (12.54\%) visited at noon hour 12-1 pm. Bodlah and Waqar (2013) reported the peak foraging time for pollinators in hot weather is early morning hour. The pollinator's activity depends on environmental factors, such as temperature and humidity (Ahmad and Aslam, 2002). This could have influenced in this study too. 
Table 1. Relative abundance of eggplants flower visitors at Khumaltar, Lalitpur, 2012-2014

\begin{tabular}{lllll}
\hline Insect species & Order & Family & Abundance frequency $(\%)$ & Ranking \\
\hline Andrena sp. & Hymenoptera & Andrenidae & $2.77(\mathrm{n}=32)$ & VI \\
Anthophora sp. & Hymenoptera & Apidae & $3.26(\mathrm{n}=40)$ & V \\
Apis cerana F. & Hymenoptera & Apidae & $11.36(\mathrm{n}=126)$ & III \\
Apis mellifera L. & Hymenoptera & Apidae & $11.95(\mathrm{n}=138)$ & II \\
Bombus sp. & Hymenoptera & Apidae & $60.22(\mathrm{n}=683)$ & $\mathrm{I}$ \\
Halictus sp. & Hymenoptera & Halictidae & $1.19(\mathrm{n}=12)$ & VII \\
Syntomis sp. & Lepidoptera & Syntomidae & $9.25(\mathrm{n}=102)$ & IV \\
\hline
\end{tabular}

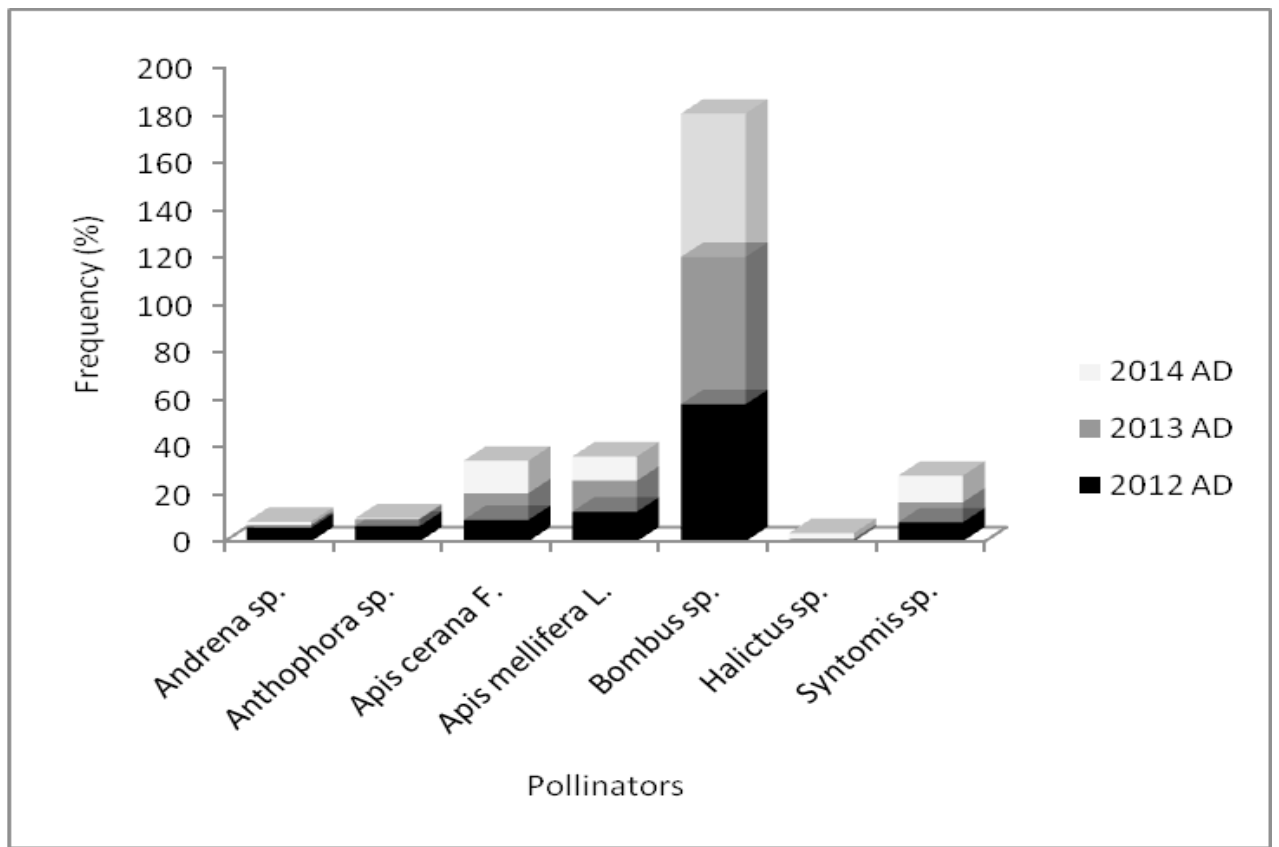

Figure 1. Abundance of eggplant flower visitors at Khumaltar, Lalitpur, 2012-2014

Table 2. Number of insects visiting eggplant flower at different time interval in Khumaltar, Lalitpur, 2012-2014

\begin{tabular}{|c|c|c|c|c|}
\hline \multirow{2}{*}{ Insect species } & \multicolumn{3}{|c|}{ Mean flower visitors observed at indicated times of day $\pm \mathrm{SE}$} & \multirow{2}{*}{ F-test } \\
\hline & $7-8 \mathrm{am}$ & $12-1 \mathrm{pm}$ & $3-4 \mathrm{pm}$ & \\
\hline Andrena sp. & $0.35^{\mathrm{a}} \pm 0.032$ & $0.13^{\mathrm{b}} \pm 0.023$ & $0.17^{\mathrm{b}} \pm 0.025$ & $*$ \\
\hline Anthophora sp. & $0.44^{\mathrm{a}} \pm 0.012$ & $0.14^{\mathrm{c}} \pm 0.035$ & $0.26^{\mathrm{bc}} \pm 0.110$ & $*$ \\
\hline Apis cerana $\mathrm{F}$. & $1.44^{\mathrm{a}} \pm 0.042$ & $0.40^{\mathrm{c}} \pm 0.033$ & $0.79^{b} \pm 0.024$ & $* *$ \\
\hline Apis mellifera $\mathrm{L}$. & $1.65^{\mathrm{a}} \pm 0.057$ & $0.29^{\mathrm{c}} \pm 0.027$ & $0.94^{\mathrm{b}} \pm 0.039$ & $* *$ \\
\hline Bombus sp. & $8.81^{\mathrm{a}} \pm 0.482$ & $1.46^{\mathrm{c}} \pm 0.133$ & $3.96^{\mathrm{b}} \pm 0.254$ & $* *$ \\
\hline Halictus sp. & $0.15^{\mathrm{a}} \pm 0.016$ & $0.06^{b} \pm 0.013$ & $0.04^{\mathrm{b}} \pm 0.011$ & $* *$ \\
\hline Syntomis sp. & $0.96^{\mathrm{a}} \pm 0.016^{2}$ & $0.48^{\mathrm{c}} \pm 0.014$ & $0.69^{b} \pm 0.017$ & $*$ \\
\hline
\end{tabular}

Means followed by same alphabet do not differ significantly by DMRT at $\mathrm{p}<0.05$; * = significant at $\mathrm{p}<0.05 ; * *=$ significant at $\mathrm{p}<0.01 ; \mathrm{SE}=$ Standard error 


\section{CONCLUSION}

Seven insect species from four families visited eggplant flowers under field condition of Khumaltar, among which Hymenopteran insects were found to be the most dominant. Bombus species visited the eggplant flower most frequently followed by domesticated bees and other insects. Insects most frequently foraged on eggplant flower at morning hour, i.e. 7-8 am than noon and evening hours. This might have favored by the cool temperature as majority of the pollinators are said to prefer cool and calm weather. The monitoring of flower visitors and their best time of foraging have to be continued in order to have good understanding of flower visitors and pollinators of eggplant, rearing and utilization of efficient pollinators and determination of diversity and abundance, which will support to sustainable agriculture production without disturbing the natural balance.

\section{ACKNOWLEDGEMENTS}

The authors are grateful to Nepal Agricultural Research council (NARC) for financial and technical support.

\section{REFERENCES CITED}

Abak, K., M. Sari and M. Paksoy. 1995. Factors affecting plant height and yield of eggplant. J. Sustain. Agric. 10: 37-47.

Ahmed, M., and M. Aslam. 2002. Pollinators visiting carrot (Daucus carota L.) seed crop, J. Res. (Sci) (BZU, Multan) 13(1):31-35.

Bodlah, I. and M Waqar. 2013. Pollinators visiting summer vegetables ridge gourd (Luffa acutangula (L.)), bitter gourd (Momordica charantia L.) and brinjal (Solanum melongena L.) Asian J Agri Biol. 1(1): 8-12.

Duncan, D. B. 1951. A significance test for differences between ranked treatment means in an analysis of variance. Va. J. Sci., 2: 171-189.

Gemmill-Herren, B. and A. O. Ochieng. 2008. Role of native bees and natural habitats in eggplant (Solanum melongena L.) pollination in Kenya. Agric. Ecosys. and Environ. 127: 31-36.

Klein, A.M, B. E Vaissière and T. Tscharntke. 2007. Importance of pollinators in changing landscapes for world crops. Proc. Biol. Sci. 274 (1608): 303-313.

Kowalska, G. 2008. Flowering biology of eggplant and procedures intensifying fruit set-review. Acta Scientiarum Polonorum, Hortorum Cultus 7(4): 63-76.

Miyamoto, M., M. Ono, M. Sasaki, H. and I. Kenmochi. 2006. Development of fruiting promotion system using honeybees in semi-forced eggplant culture. Effectiveness of pollination by the European honeybee. Japanese J. Appl. Entomol. and Zool. 50(4): 297-304.

Montemor, K. and D. T M. Souza. 2009. Pollinators biodiversity and floral biology on eggplant crop (Solanum melongena L.). Zootecnia Trop. 27(1): 97-103.

Nunes-Silva, N., M. Hrncir and V. L. Imperatriz-Fonseca. 2010. Pollination by vibration. Oecologia Australis 14(1): 140-151.

Patricio, G. B., B. B. Grisolia, I. C. Desuoacute, P. C. Montagnana, F. G. Brocanelli, E.G. Gomig and M. J. O. De Campos. 2012. The importance of bees for eggplant cultivations (Hymenoptera: Apidae, Andrenidae, Halictidae). Sociobiol. 59(3): 1037-1052.

Thapa, R. B. 2006. Honeybees and other insect pollinators of cultivated plants: A review J. Inst. Agric. Anim. Sci. 27:1-23. 